\title{
Analysis of Suspension System for 3D Printed Mobile Robot
}

\author{
H.S. SUCUOGLU ${ }^{1}$, I. BOGREKCI ${ }^{1}$, P. DEMIRCIOGLU ${ }^{1}$, O. TURHANLAR ${ }^{1}$
}

\author{
Accepted $3^{\text {rd }}$ September 2016
}

\begin{abstract}
In this study, 3D printed mobile robot with suspension system was analysed using Computer Aided Engineering (CAE) methods. Spring and damping coefficients of the suspension system were determined. Structural and dynamic analyses were conducted after the selection of appropriate spring and damping coefficients to find structural strength and power requirement of mobile robot. The length of robot and the number of wheels were decreased to one third of the real to ease the analysis. A concrete road with the length of $1,000 \mathrm{~mm}$ and $10^{\circ}$ inclination was created as ground to simulate the real world. Obstacles with the height of $80 \mathrm{~mm}$ were placed on different locations on the path of the wheels for the robot. The designed suspension system was consisted of; two dashpots connected to wheels and body through connection components and a spring between two wheels to ensure the stability. Polylactic acid (PLA) was used as body material. In the structural part; the strength of the robot body and critical part (suspension leg) was computed by Finite Element Analysis (FEA). Safety factor values for body and critical component were found as almost 7 and 4, respectively. The results from the analysed indicated that maximum equivalent stresses and strains (for body $\sigma_{\max }=3.4 \mathrm{MPa}, \quad \varepsilon_{\max }=3 \mathrm{e}-3 \mathrm{~mm} / \mathrm{mm}$ and for critical component $\sigma_{\max }=6.5 \mathrm{MPa}, \varepsilon_{\max }=6 \mathrm{e}-3 \mathrm{~mm} / \mathrm{mm}$ ) were occurred while robot was passing the obstacles. In dynamic analysis; robot was driven with three different speeds $(0.25,0.5$ and 1 metre per second) on the same road conditions. The motor torque and force values, suspension system results (force and elongation), angular velocity of the wheels and power requirement of mobile robot were calculated. The results showed the power requirement of robot was 70 Watt when it was driven with maximum velocity.
\end{abstract}

Keywords: Computer Aided Engineering, Finite Element Analysis, Polylactic Acid, Suspension System, 3D Printed Mobile Robot

\section{Introduction}

Robots are increasingly entering the area of many technical studies and research. Recently; robotic industry is improving and evolving rapidly to satisfy the needs of markets, daily use of people, manufacturing, research projects and universities etc. [1]. Mobile robot is one of the most common type of robotic types. A mobile robot has unlimited movement to complete its mission. They can be used to perform a variety of tasks normally carried out by humans such as surveillance, exploration, patrol, fire searching-fighting, homeland security and care taker etc. [2]. A mobile robot system consists of a platform moved by locomotive elements. The locomotive system depends firstly on the environment that the robot operates. These environment can be aerial, aquatic and terrestrial. In the aquatic and aerial environments, the locomotive systems are generally propellers or screws. The locomotive system in terrestrial environment is complicated. Wheels, tracks and legs are the typical terrestrial locomotive elements [3].

Rapid prototyping techniques are nowadays used in product development process. They allow for fast, low-cost and easy manufacturing series of components directly from the component geometry stored in CAD model. This prototyping process allows for assessment of many aspects of functionality, dimensional, physical and esthetical adaptation of components in the developed product [4]. 3D printing technology is one of the most

${ }^{I}$ Department of Mechanical Engineering, Faculty of Engineering, Adnan Menderes University, Aydin/Turkey

Note: This paper has been presented at the $3^{\text {rd }}$ International Conference on Advanced Technology \& Sciences (ICAT'16) held in Konya (Turkey), September 01-03, 2016. common types of rapid prototyping techniques.

As 3D printers become more prevalent among users they are being used to manufacture more diverse objects. This has included components that either replace items normally purchased or are uniquely designed for the specific needs of the user in terms of geometry and function [5].

Different types of suspension systems are used for mobile robots that operates at terrestrial environment to ease the adoption to usage area and to increase the flexibility and motion ability. Suspension systems of mobile robots are generally designed and produced using dashpots, return and compressing springs.

It is an easy and low-cost way of using $3 \mathrm{D}$ printing technology to produce the components of a mobile robot prototype. After CAD and $\mathrm{CAE}$ process; mobile robot for any environment can be created and checked for final product. It is a great way for designers and researcher to decrease the modelling and manufacturing time and cost. 3D printing technology opens a new way with the advantages summarized below [6];

- Fast prototyping for mobile robot platforms

- Decreasing the time and cost of modelling and manufacturing

- Easy configuration and adaptation

- Motivation for the development of new types of products

In this article we focused on the development of 3D printed mobile robot with suspension system. After design process; solid state model of mobile robot was analysed using Computer Aided Engineering (CAE) methods. Spring and damping coefficients of the suspension system were determined. Structural and dynamic analyses were conducted. Important design and manufacturing parameters were determined using analyses and real world test results. 


\section{Design of 3D Printed Mobile Robot}

Mobile robot (Fig. 1) was designed using CAD tools. In the design process; several issues were considered such as compact size, modularity, time and cost. The most important point of the design was compliance with additive manufacturing technique for all of the components except wheels, electric motors and suspension system. Body and connection components were produced using 3D printing technology. The sizes, thickness, shape of the parts were taken into consideration that affect the manufacturing process using $3 \mathrm{D}$ printer. Complexity of the components were decreased to save time-material and to improve the robot's performance.

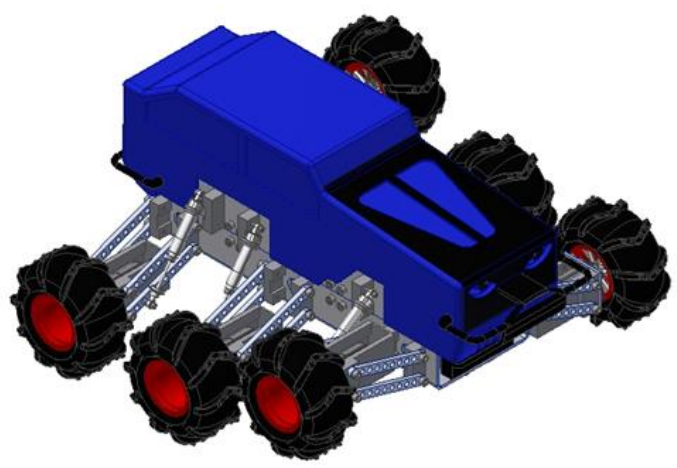

Figure 1. Designed 3D printed off-road mobile robot

\subsection{Geometry and 3D Model}

All of the parts for the robot were prepared using parametric solid modelling technique. The required connectors, channels and supports for the wheels, electric motors and suspension components were designed using technical data sheet and drawings. The assembly model was created and compatibility of the manufactured parts and commercially available components were checked in assembly model. Designed off-road mobile robot has six independent wheel-motor-suspension systems. The details of the traction system for the mobile robot are depicted in Fig. 2 and Table 1.

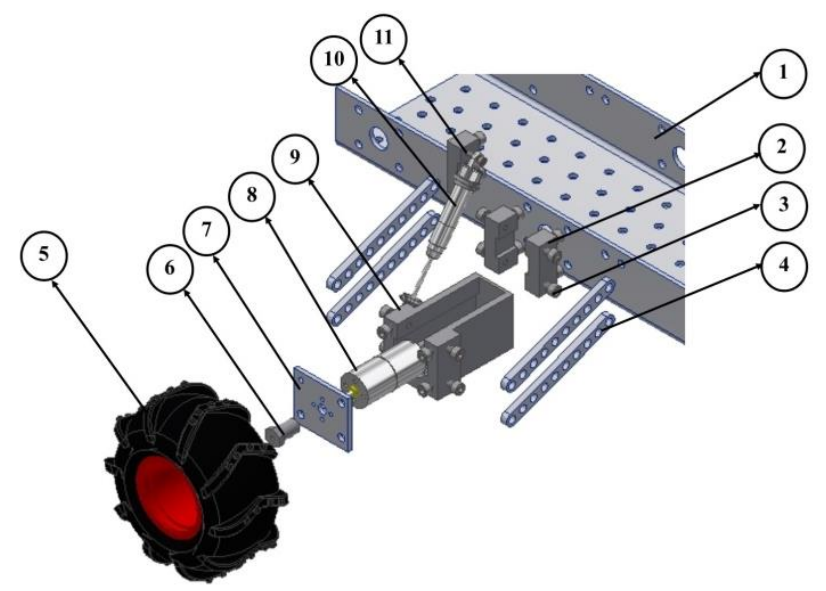

Figure 2. Exploded view of mobile robot traction system
Table 1. Traction system details

\begin{tabular}{|c|c|c|}
\hline Number & $\begin{array}{l}\text { Component } \\
\text { Name }\end{array}$ & Explanation \\
\hline 1 & Sub chassis & It is bottom body of the mobile robot. \\
\hline 2 & $\begin{array}{l}\text { Body } \\
\text { connector }\end{array}$ & $\begin{array}{c}\text { Body connectors are used for } \\
\text { suspension leg-chassis connections. }\end{array}$ \\
\hline 3 & $\begin{array}{l}\text { Connection } \\
\text { screw }\end{array}$ & $\begin{array}{l}\text { Different types of screws are used for } \\
\text { connection and suspension motions. }\end{array}$ \\
\hline 4 & $\begin{array}{l}\text { Suspension } \\
\text { Leg }\end{array}$ & $\begin{array}{l}\text { It is the critical part of the robot } \\
\text { suspension system. The mobility of the } \\
\text { suspension system is provided with } \\
\text { suspension leg. }\end{array}$ \\
\hline 5 & Wheel & It is for the motion of mobile robot. \\
\hline 6 & $\begin{array}{l}\text { Wheel-motor } \\
\text { connector }\end{array}$ & $\begin{array}{l}\text { It is used as shaft between motor and } \\
\text { wheel. }\end{array}$ \\
\hline 7 & $\begin{array}{l}\text { Wheel-case } \\
\text { connector }\end{array}$ & $\begin{array}{l}\text { It is for the connection between wheel } \\
\text { and motor protection case. }\end{array}$ \\
\hline 8 & Electric motor & It is used for actuation. \\
\hline 9 & Motor case & $\begin{array}{l}\text { As the robot is designed as off-road, } \\
\text { motor protection case is designed and } \\
\text { manufactured. }\end{array}$ \\
\hline 10 & Dashpot & $\begin{array}{l}\text { It is suspension system element. The } \\
\text { robot can climb and pass the obstacles } \\
\text { using this component. }\end{array}$ \\
\hline 11 & $\begin{array}{l}\text { Dashpot-body } \\
\text { connector }\end{array}$ & $\begin{array}{l}\text { It is for suspension system-body } \\
\text { connection. }\end{array}$ \\
\hline
\end{tabular}

\subsection{Suspension System Design}

$3 \mathrm{D}$ printed mobile robot was designed and manufactured as off-road vehicle prototype. So the suspension system was most critical for the operation at challenging terrain. It should be optimized for body stability, to improve the motion capability and to decrease the energy consumption.

For the suspension six dashpots and three return springs were used. Dashpots, were connected between wheel legs and body to climb and pass the obstacles. Springs were placed between wheels horizontally for motion and body stability.

Spring and damping coefficients were determined using catalogue values. The total weight of the robot was about $6 \mathrm{~kg}$ so load for each wheel was $1 \mathrm{~kg}$. Using the information and catalogue values 5 different spring and damping coefficients were applied at Matlab Simulink simulation environment. (For Sys1; $\mathrm{k}=150 \mathrm{~N} / \mathrm{m} \quad \mathrm{b}=50 \mathrm{Ns} / \mathrm{m}$, Sys $2 ; \mathrm{k}=250 \mathrm{~N} / \mathrm{m} \quad \mathrm{b}=75 \mathrm{Ns} / \mathrm{m}$, Sys3; $\mathrm{k}=350 \mathrm{~N} / \mathrm{m} b=100 \mathrm{Ns} / \mathrm{m}$, Sys $4 ; \mathrm{k}=750 \mathrm{~N} / \mathrm{m} \quad b=125 \mathrm{Ns} / \mathrm{m}$, Sys 5 ; $\mathrm{k}=1,000 \mathrm{~N} / \mathrm{m} \mathrm{b}=150 \mathrm{Ns} / \mathrm{m}$ ). The optimum coefficient values were determined as $350 \mathrm{~N} / \mathrm{m}$ and $100 \mathrm{Ns} / \mathrm{mm}$ for spring and damping respectively for flexibility and stability.

Using these coefficients; dashpots and springs were selected easily. The length of the aluminium dashpot shown in Fig. 3 was $11 \mathrm{~cm}$ that provides capability to the robot to pass the obstacles up to $10 \mathrm{~cm}$ without climbing.

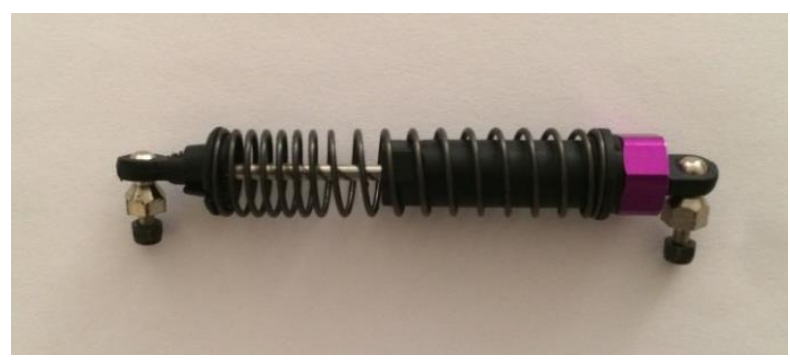

Figure 3. Selected dashpot for robot suspension system 


\subsection{Material of Mobile Robot}

Rapid Prototyping Systems produce objects generally from acrylonitrile butadiene styrene (ABS) and polylactic acid (PLA). These materials have low enough melting temperatures to use in melt extrusion in a dedicated machine and high enough temperature for prints to retain their shape at average use temperatures [7].

Usually, plastics as PLA or ABS are used as raw material to feed 3D printers. However, environmental pollution made by plastics is a real problem to solve. For that reason, PLA is used more and more. It is biodegradable, thermoplastic and semi crystalline [8].

ABS; strength, flexibility, machinability, and higher temperature resistance make it often a preferred plastic for engineers, and professional applications. It is strong, flexible, with good machinability and a higher temperature resistance. These properties can make it more popular for use in professional applications. PLA; the wide range of available colours and translucencies attract those who print for display or general uses. When properly cooled, PLA seems to have higher maximum printing speeds, lower layer heights, and sharper printed corners. Combining this with low fault on parts make it a popular plastic for general printers, hobbyists, and schools [9]. Mechanical properties of PLA and ABS are given in Table 2.

Table 2. Mechanical properties PLA and ABS[10]

\begin{tabular}{|c|c|c|}
\hline Properties & PLA & ABS \\
\hline Density $\rho(\mathrm{Mg} / \mathrm{m})$ & 1.25 & $1.01-1.21$ \\
\hline Young Modulus E $(\mathrm{GPa})$ & 3.5 & $1.1-2.9$ \\
\hline Elongation at break $(\%)$ & 6 & $3-75$ \\
\hline Melting (softening) temperature Tm $\left({ }^{\circ} \mathrm{C}\right)$ & 160 & $88-128$ \\
\hline Yield Stress $\sigma_{\mathrm{y}}(\mathrm{MPa})$ & - & $18.5-51$ \\
\hline Tensile Strength $\sigma_{\mathrm{ts}}(\mathrm{MPa})$ & $36-55$ & $25-50$ \\
\hline Ultimate Tensile Strength $\mathrm{UTS}(\mathrm{MPa})$ & 35 & $33-110$ \\
\hline Strength to weight ratio $(\mathrm{kN}-\mathrm{m} / \mathrm{kg})$ & 40 & $31-80$ \\
\hline Shear modulus $\mathrm{G}(\mathrm{GPa})$ & 2.4 & - \\
\hline
\end{tabular}

\subsection{Manufacturing of Mobile Robot}

All of the parts of mobile robot; connectors, suspension legs, bodies, motor-electronic protection cases and body shell were designed and manufactured using 3D printing technology and PLA material (Fig. 4). The weight of manufactured parts and commercially available components (wheels, motors, suspension elements and connection screws) were about 3.5 and $2.5 \mathrm{~kg}$ respectively. As a result an off-road light weight mobile robot prototype with $6 \mathrm{~kg}$ was designed and manufactured.

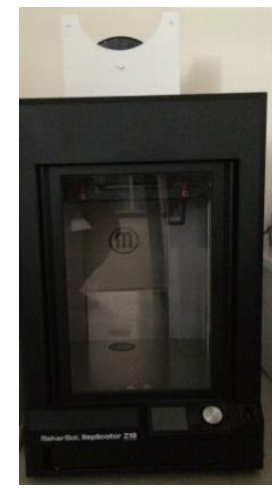

(a)

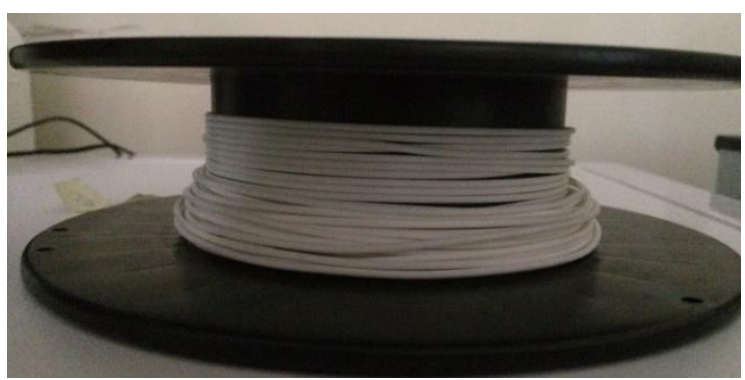

(b)

Figure 4. 3D printing technology (a) 3d printer (b) PLA filament

\section{Analyses}

\subsection{Structural Analysis}

Structural analysis was conducted after the selection of suitable material, spring and damping coefficients to find structural strength for whole robot's body and critical components using Ansys Workbench Static Structural Module. Safety factors, maximum equivalent stresses and strains for whole body and critical component (suspension leg) were calculated.

The length of robot and number of wheels were decreased to one third of the real to ease the analysis. A concrete road with the length of $1,000 \mathrm{~mm}$ and $10^{\circ}$ inclination was created as ground to simulate the real world. Obstacles with height of $80 \mathrm{~mm}$ were placed on different locations on the path of the wheels for the robot. The strength of the robot body and critical part was performed by Finite Element Analysis (FEA).

In the first part of structural analysis (Fig. 5); static loads were applied to mobile robot. These loads were; self-weight of the robot about $2.5 \mathrm{~kg}$, other supressed weights such as battery and electronic protection case $(1.5 \mathrm{~kg})$ and the forces caused by suspension leg motion while it was passing the obstacles.

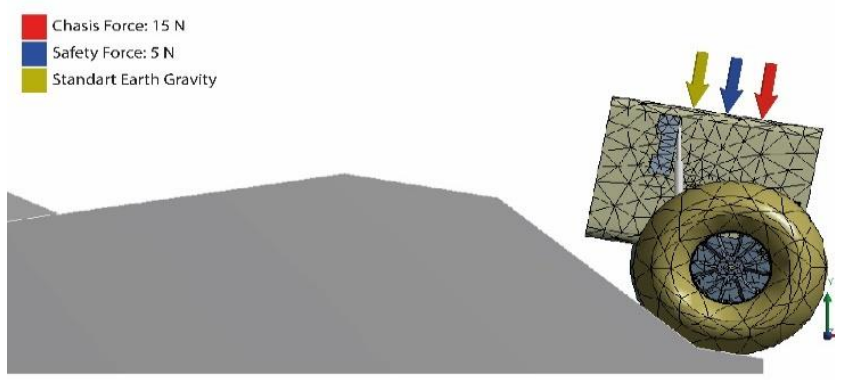

Figure 5. Structural analysis with static loads

A crash analysis was carried out with 1 and $2 \mathrm{~m} / \mathrm{s}$ velocities in the second part of structural analysis (Fig. 6) Although the maximum speed of the robot was $1 \mathrm{~m} / \mathrm{s}$ twice more impact force was applied because of slow down distance effect and for safety. The impact forces were calculated with formula shown below.

F.s $=1 / 2 \mathrm{~m} \mathrm{x} \mathrm{V}^{2}$

$\mathrm{F}=1 / 2 \mathrm{mx} \mathrm{V}^{2} / \mathrm{s}$

Where:

F.s $\quad$ Slow down force (N)

$\mathrm{F} \quad$ Impact force $(\mathrm{N})$

$\mathrm{m} \quad$ Mass $(\mathrm{kg})$ 
Slow down distance was assumed as $8 \mathrm{~mm}$ using experimental application. Using the formula (1) and (2), the impact forces were calculated for 1 and $2 \mathrm{~m} / \mathrm{s}$ velocities;

$\mathrm{F}=1 / 2 \mathrm{~m} * \mathrm{~V}^{2} / \mathrm{s}=1 / 2 \times 4 \times 1^{2} / 0.008=250 \mathrm{~N}$

$\mathrm{F}=1 / 2 \mathrm{~m} * \mathrm{~V}^{2} / \mathrm{s}=1 / 2 \times 4 \times 2^{2} / 0.008=500 \mathrm{~N}$

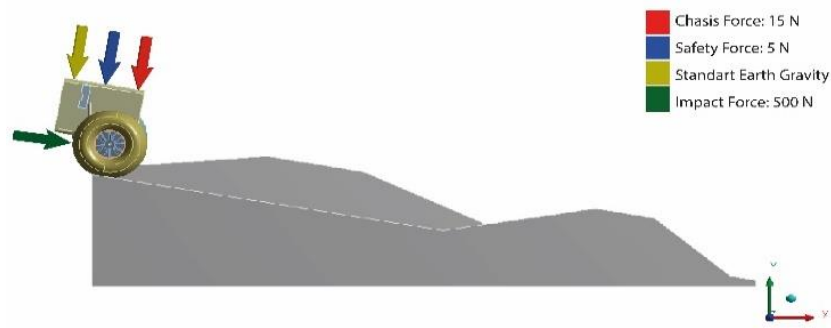

Figure 6. Crash analysis

\subsection{Dynamic Analysis}

Dynamic analysis was carried out using Ansys Workbench Rigid Dynamics Module. Mobile robot was driven with three different speeds $(0.25,0.5$ and 1 metre per second) on the same road condition with structural analysis. Rotational velocities were defined to wheels to create the displacement motion. Suspension leg connections were assigned as rotary joints. Joint loads were applied $50^{\circ}$ to pass the placed obstacles. The required information for motor selection; torque and force values, suspension system results (occurred force and elongation), angular velocity of the wheels and power requirement of mobile robot was calculated in dynamic analysis (Fig. 7).

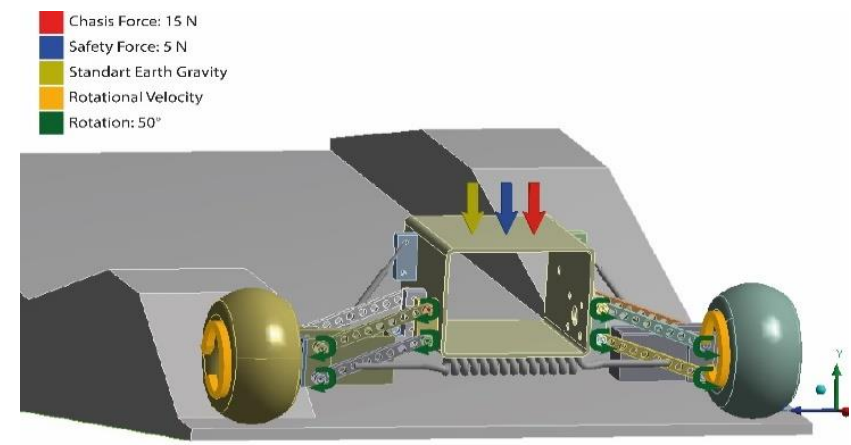

Figure 7. Dynamic analysis

\section{Results and Discussion}

\subsection{Structural Analysis}

Structural analysis results under static loads are given in Table 3.
Table 3.Structural analysis results under static loads

\begin{tabular}{|c|c|}
\hline Criteria & Values \\
\hline Equivalent stress body $(\mathrm{MPa})$ & 3.5 \\
\hline Equivalent stress critical component $(\mathrm{MPa})$ & 6.5 \\
\hline Equivalent strain body $(\mathrm{mm} / \mathrm{mm})$ & 0.003 \\
\hline Equivalent strain critical component $(\mathrm{mm} / \mathrm{mm})$ & 0.006 \\
\hline Safety factor for whole body & 7 \\
\hline Safety factor for critical component & 4 \\
\hline
\end{tabular}

The total calculated maximum equivalent stresses for whole body and critical components were found about 3.5 and 6.5 $\mathrm{MPa}$ respectively. The calculated stresses are not overcome the strength of PLA material. Safety factor values for both body and critical components ( 7 for whole body 4 for critical component) showed that robot can operate under static loads safely. However; mobile robot's prototype was designed for off-road operation. To get more reliable results; crash analysis with calculated impact force was conducted in structural analysis. 250 and $500 \mathrm{~N}$ forces were applied to robot front wheels to create the crash simulation. Crash analysis results with 250 and $500 \mathrm{~N}$ impact forces are given in Table 4.

Table 4.Crash analysis results

\begin{tabular}{|c|c|c|}
\hline Criteria & $250 \mathrm{~N}$ & $500 \mathrm{~N}$ \\
\hline Equivalent stress body $(\mathrm{MPa})$ & 5 & 12 \\
\hline Equivalent stress critical component $(\mathrm{MPa})$ & 13 & 27 \\
\hline Equivalent strain body (mm/mm) & 0.004 & 0.01 \\
\hline Equivalent strain critical component (mm/mm) & 0.012 & 0.024 \\
\hline Safety factor for whole body & 5 & 2 \\
\hline Safety factor for critical component & 2 & 0.9 \\
\hline
\end{tabular}

As understood from the results that equivalent stresses caused by 250 and $500 \mathrm{~N}$ impact forces were almost twice and four times greater than occurred stresses with static loads for critical component. The calculated safety factor decreased from 4 to 2 with $250 \mathrm{~N}$ that arose from $1 \mathrm{~m} / \mathrm{s}$ velocity crash.

The safety factor was found as 0.9 with $2 \mathrm{~m} / \mathrm{s}$ velocity crash. It can be understood that this component was broken with this applied speed. Critical component is not strong enough for crash scenario occurred with $2 \mathrm{~m} / \mathrm{s}$ velocity. Crash test was also applied in real world application. It was observed that both in analysis and real world; suspension leg was broken at similar area (Fig. 8).

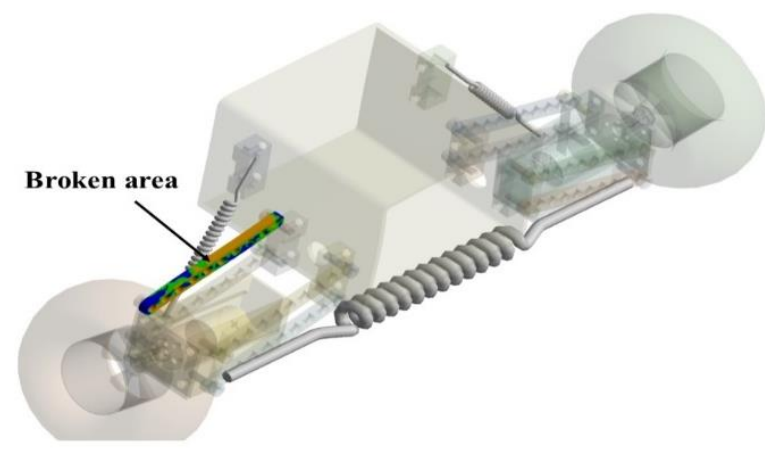


(a)

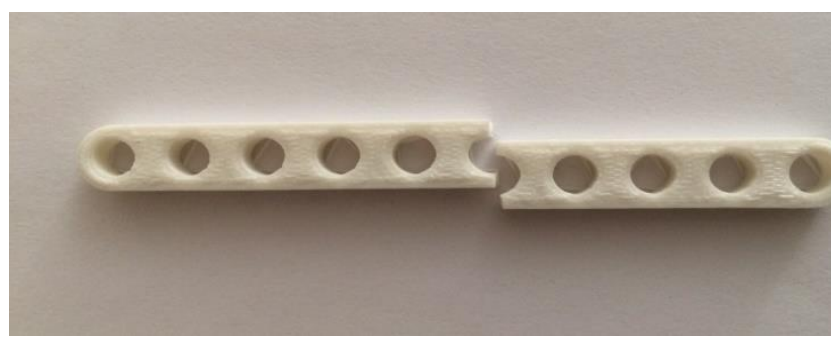

(b)

Figure 8. Broken part (a) Simulation (b) Experimental

\subsection{Dynamic Analysis}

The power requirement of mobile robot was found as 18,35 and 71 Watt for $0.25,0.5$ and $1 \mathrm{~m} / \mathrm{s}$ speeds. As the number of wheels and length of robot were decreased to one third of the real to ease the analysis the calculated power requirement was for one third of whole system. The total power requirement is about 213 Watt. Using these information electric motors were selected with the values of 6 volt voltage and 6.2 ampere maximum current. Using 6 electric motors system can supply 223 Watt power and it is sufficient for calculated power requirement.

The other results of dynamic analysis are given in Table 5 . Dashpot and spring forces-elongations were found as $14 \mathrm{~N}-42$ $\mathrm{mm}$ and $2.5 \mathrm{~N}$ and $7 \mathrm{~N}$. Maximum torque requirements for electric motor were about 528, 618 and 1,000 N.mm for 0.25, 0.5 and $1 \mathrm{~m} / \mathrm{s}$ speed values.

Table 5.Dynamic analysis results

\begin{tabular}{|c|c|c|c|}
\hline Criteria & $0.25 \mathrm{~m} / \mathrm{s}$ & $0.5 \mathrm{~m} / \mathrm{s}$ & $1 \mathrm{~m} / \mathrm{s}$ \\
\hline Power requirement (Watt) & 18 & 35 & 71 \\
\hline Dashpot force (N) & 14 & 14 & 14 \\
\hline Dashpot elongation (mm) & 42 & 42 & 42 \\
\hline Spring force (N) & 2.5 & 2.5 & 2.5 \\
\hline Spring elongation (mm) & 7 & 7 & 7 \\
\hline Motor force (N) & 8 & 8.7 & 9.5 \\
\hline Motor torque (N.mm) & 528 & 618 & 1,000 \\
\hline Angular velocity (rad/s) & 0.38 & 0.78 & 1.5 \\
\hline
\end{tabular}

\section{Conclusion}

In this study, 3D printed off-road mobile robot prototype with suspension system was designed and analysed using Computer Aided Engineering (CAE) methods. Spring and damping coefficients of the suspension system were determined. Structural and dynamic analyses were conducted to find structural strength and power requirement of mobile robot. After design and analysis stages body and connection components of mobile robot prototype were manufactured using $3 \mathrm{D}$ printing technology. The selected results obtained from analyses and real world application were presented. The safety factor of whole body and critical component were calculated as 5 and 2 in crash analysis with 250 $\mathrm{N}$ impact force that occurred when robot is driven with $1 \mathrm{~m} / \mathrm{s}$ velocity. It can be concluded that the structural material (PLA) could ensure the safety when robot is charged with $250 \mathrm{~N}$ impact force.

\section{References}

[1] K. S. Rawat and G. H. Massiha. "A hands-on laboratory based approach to undergraduate robotics education. In Robotics and Automation," Proceedings. ICRA'04. 2004 IEEE International Conference on Vol. 2, pp. 1370-1374. IEEE, 2004.

[2] X. Q. Chen, J. G. Chase and Y. Q. Chen. "Mobiles RobotsPast Present and Future". INTECH Open Access Publisher, 2009.

[3] E. Garcia, M.A. Jimenez, P.G. De Santos and M. Armada. "The Evolution of Robotics Research". IEEE Robot. Autom. Mag. 14(1), 90-103, 2007.

[4] J. Czyżewski, P. Burzyński, K. Gaweł and J. Meisner. "Rapid prototyping of electrically conductive components using 3D printing technology". Journal of Materials Processing Technology, 209(12), 5281-5285, 2009.

[5] B. Tymrak, M. Kreiger, and J. M. Pearce. "Mechanical properties of components fabricated with open-source 3-D printers under realistic environmental conditions". Materials \& Design, 58, 242-246, 2014.

[6] J. G. Gomez, A. V. Gomez, A. P. Moreno and M. Abderrahim. "A new open source 3D-printable mobile robotic platform for education". In Advances in autonomous mini robots (pp. 49-62). Springer Berlin Heidelberg, 2012.

[7] F. Cruz, S. Lanza, H. Boudaoud, S. Hoppe and M. Camargo. "Polymer Recycling and Additive Manufacturing in an Open Source context: Optimization of processes and methods".

[8] R. S. Madani, E. Baines, A. Moroz and B. Makled. "Evaluation of Suitability of Rapid Prototyping Techniques for Use by Children Evaluation", 2015.

[9] B. D. Harris, S. Nilsson, and C. M. Poole. "A feasibility study for using ABS plastic and a low-cost 3D printer for patient-specific brachytherapy mould design". Australasian Physical \& Engineering Sciences in Medicine, 38(3), 399412, 2015.

[10] Kalpakjian and S. R. Schmid. "Manufacturing Processes for Engineering Materials-5th Edition". Agenda, 12, 1, 2014. 